\title{
Emotional apprenticeships: reflection on the role of academic practice in the construction of 'the field'
}

\author{
By Celayne Heaton Shrestha (University of Sussex)
}

This contribution is concerned with the 'emotional regime(s)' (e.g. Reddy 2002) of academic anthropology, and the processes and practices through which 'the field' continues to be constructed as an entity separate from everyday life. 'The field' has been the subject of considerable attention in recent years, as have the textual, social, and conceptual strategies of distanciation involved in its construction. The role of emotions and emotion work in this process, on the other hand, has generally been overlooked. In this article, I draw on my own changing emotions towards the subjects of research during my postgraduate training to show how particular feelings towards the subject of research were legitimised and their expression and sensation encouraged - while others were delegitimised and discouraged - through educational practices such as seminars. The article shows that the transformation in emotional tone (and experience) involved - not the suppression of emotion, as has often been argued in anthropological writingsbut a change in emotional style. The paper argues that this change in emotional style - and the 'emotional regime' that supported it - contributed to the 'Othering' of the subjects of research, as well as recasting researcher and researched in a hierarchical relation to each other. Thus, the article suggests that emotional apprenticeship in the academic setting plays a key role in the enduring construction of 'the field' as involving distance and separation from personal areas of activity.

\section{Introduction: situating emotions}

Our emotions as researchers, in particular towards our subjects of research, tend to go through changes. This raises questions about the ways in which 'the field' is constructed across different institutional settings. This theme has received considerable attention in recent years, as indicated, for instance, by the volume edited by Amit (2000) Constructing the Field, or the 2004 ASA (Association of Social Anthropologists of the UK and Commonwealth) conference Locating the Field: Metaphors of Space, Place and Context in Anthropology. These debates have acknowledged the centrality of 'the field' and fieldwork to the anthropological endeavour, while also questioning their naturalness. 'The field' is no longer seen as 'simply existing' and awaiting discovery; something that one 'enters' and 'leaves'. Rather, the distance that represents a badge of ethnographic authenticity (e.g. Kleinman and Copp 1993) is understood to require active construction. Writers have variously pointed to textual (e.g. Clifford and Marcus 1986), social (e.g. Amit 2000) and conceptual (e.g. Rapport 2000) strategies of distanciation, while the ASA conference has broadened the scope of these debates, drawing attention to the global social processes that are transforming the meanings of 'the field' and 'fieldwork' in anthropology. Questions are now being asked about the necessity of total immersion, and 
the importance of distance to anthropological understanding. Coleman argues that 'contemporary anthropology now accepts that the notion of the isolated, autonomous fieldwork site has been something of a convenient functionalist fiction' (2004:26). However, it seems that in practice, the need for compartmentalisation of fieldwork still prevails. Amit, for instance, comments:

\begin{abstract}
Anthropologists whose principal methodology has rested on a maverick if sometimes uneasy melding of these domains [work and home, the personal and the professional] have nonetheless attempted to uphold their overall separation by compartmentalizing fieldwork spatially, temporally and textually. (2000:3)
\end{abstract}

My purpose here is to explore further the role played by everyday practices of anthropological knowledge production in the construction of 'the field' as distant and removed from everyday life. I do so as I believe that existing accounts have overlooked two important elements of this process: firstly, the role of emotions and emotion work, and secondly, the role played by academic practices in the construction of anthropological fields and subjects. In order to illustrate this point, I will use a passage from my thesis as a trigger for reflection. I reflect on the emotions it portrays, the emotional tone it bears, and the emotional response it arouses in me, upon rereading, at a much later date - more specifically, towards the end of my $\mathrm{PhD}$ training. ${ }^{1}$ The vignette itself, on the other hand, was written up soon after my return from 'the field' among fieldworkers in a national development NGO in Nepal. The timeline for the emotion work that I describe here spans the fieldwork stage to the completion of the $\mathrm{PhD}$.

My analysis of the vignette and the emotional changes it brings to light is informed by a view of emotions associated with 'psychocultural anthropologists' (e.g. Chodorow 1999, Kracke 1987, or Obeyesekere 1990), namely that human beings everywhere have some sort of internal life, and that selves, emotions and powerful experiences are there to be described. This view is rejected by 'anthropologists of self and feeling' such as M.Z. Rosaldo (1984), Lutz or Abu-Lughod (e.g. Lutz and Abu-Lughod 1990), for whom emotions are solely public and social phenomena. I sympathise with the motivation that drives the work of anthropologists of self and feeling, namely, a suspicion of the assumptions of universality in psychoanalytical approaches to the study of emotions, and accept that we need to be wary of importing Western assumptions about the self and feeling into our analyses. However, I do not accept these scholars' contention, for several reasons. Firstly, I find unconvincing their premise that the absence of psychologising discourses among people studied indicates a lack of an internal life; the 'hypocognition' (Levy 1984) of emotions is an equally plausible explanation for this lack; the difficulty in articulating these, as Chodorow (1999) for instance reminds us, is another. Secondly, such an assumption leads to the equally questionable denial of individual agency and exaggeration of collective orientations in other cultures. Thirdly, this is at odds with my own experience of self and others, and, as Cohen (1994) argues, refusing to extend to others the complexity observed in oneself is problematic in numerous respects, and further opens oneself to charges of ethnocentrism.

\footnotetext{
${ }^{1}$ This article was originally written in late 2001 , immediately after the submission of my thesis. It has been expanded and the argument developed in a paper presented at the conference 'Surviving and Writing Up Fieldwork', Oxford, 14-15 ${ }^{\text {th }}$ September 2006.
} 
I also found Reddy's work (e.g. 2002) useful in thinking about emotions and the ways that these experiences are produced, even if, by his own admission, his arguments are not novel. Building on the work of psychocultural anthropologists, he offers a series of welldefined conceptual tools to study emotions, which are otherwise lacking in many contributions to this field: these include, inter alia, the concepts of 'emotional regime', 'emotional liberty', 'emotional refuge' and 'emotional suffering'. He further posits that three main features of emotions can be said to be universal. The first universal feature is the fact that emotions will be construed as an important domain of effort. The second universal feature is the fact that all communities will give prescriptions and counsel as to the best strategies for pursuing emotional learning, and the proper end point of emotional equilibrium. The third universal feature of emotions is that emotions and emotional expression interact in a dynamic way, and with varied outcomes. Emotional expression can confirm or disconfirm, intensify or attenuate the feeling state that is claimed; they can be either self-exploratory or self-altering. Thus, emotional expressions-following Austin's (1962) speech act theory, Reddy names these 'emotives'-have a direct impact on the feelings in question. He explains: "if asked the question "do you feel angry?" a person may genuinely feel more angry in answering yes, less angry in answering no' (Reddy 1997:331, original emphasis).

I will note one final point of Reddy's work, and that concerns the manner in which emotional styles are effected and communicated:

Such styles are best communicated by means of sensory-rich participatory performances: ritual, predication, theatre. But they may also be conveyed, or suggested, by literature, art, music, iconography, architecture, dress. All such practices and products can be viewed as emotive in character. (ibid:331)

Like Reddy, Leavitt (1996:522) urges us to look beyond words for traces of 'emotion'; he argues that emotion is not just found in language that is explicitly about emotions, but is also to be found in intonation, and in grammar. It follows that studying discourse about emotions is insufficient, and that this task requires the researcher to impute, to reconstruct, and to go beyond definitions by participants. In the same way, Wikan (1992:473) writes about how she came to grasp Balinese emotion work, in particular the notion of 'managing the heart': she observes that her understanding was formed through a variety of clues, long before she 'stumbled' across the Balinese concept of managing the heart. She mentions 'quivers in a voice', 'reading somatic complaints about overwhelming pain and suffering', and 'too many things for me to remember now, for such clues do not stand out in the fieldnotes I took'.

To summarise: when I trawl through my fieldnotes, ethnography and memory for evidence of 'emotions', therefore, I look out for emotion words or words which (in the English language equivalent) refer to 'an emotion'; expressions that refer to a inner 'feeling' or state; for the tone of voice or the mood of a written episode that, upon reading or hearing, evoke such feelings. When I write of 'emotion work', I intend to refer to work on actual feeling and not (or not only) work at the level of discourse; and as will become clear, the emotional apprenticeship which is the subject of this piece is not simply, as Beatty would argue, a 'training in language skills and social graces' (2005:30), but rather involves both the development of new ways of feeling as well as the acquisition of linguistic and social skills. 
I now turn to the vignette. In this episode, I describe NGO fieldworkers in their role as karmacarya (salaried office workers) on a busy day in a field office. This particular office was one of several established by a national NGO, with its HQ in the capital, Kathmandu, to oversee its community development programmes 'on the ground'. This passage was meant to capture the fundamental contradiction at the heart of NGO praxis in Nepalbetween the ideals of 'service' (epitomised by the fieldworker and hardships of fieldwork) and the material wealth and advantages of a professionalising 'voluntary sector' (personified by the karmacarya, his or her regular wage and comfortable working environment). The vignette suggests that professionalism trumps 'service', as fieldworkers feel at liberty to ignore a project beneficiary visiting their office. ${ }^{2}$ Their thulo manche ('V.I.P.') attitude contrasts starkly with the beneficiary's awkwardness, and his acute awareness of the wealth and status of the premises he is visiting.

It was the $2^{\text {nd }}$ of May 1997. I had gone down to the NGO field office's ground floor rooms, after discussing the results of the elections in Britain with staff working on the first floor. There, I was greeted by a familiar scene.

\section{A fieldwork episode: 'visitors to the field office'}

It is around 11a.m. Downstairs, I notice that some man has arrived in the front room. He greets me with a namaste as I enter the room. Kiren and Ram, two field officers, are sitting at the room's single desk; Ram is reading the annual progress report, a questionnaire printed and prepared by [donor] and which has been filled in in pencil by staff in the various field offices (FOs) and sub-FOs; Kiren is writing by hand the numbers read out by Ram into tables printed out by the office computer. Basanta, another field officer, has come back into the room and I ask who the man is and what he wants. Basanta tells me he's the chairman of some Savings and Credit Organisation (SCO) and he had come to get stationery. I am standing by the desk; I ask the man if he is an SCO chairman, he replies that 'yes' he's the chairman of Bahugaun's saving and loan group. Kiren and Ram read and write numbers.

Mahanta, a fieldworker, comes into the front room carrying a piece of paper - the 'detailed report' he was writing last night for the FO boss. Ram lifts his head up and informs Mahanta 'I'll be busy today until 1.30p.m. then I'll be free'. Mahanta, smiles, looking at me and jokes 'then Ram will go off wagging his tail like a dog when it's happy!' Mahanta sits next to the SCO chairman on the bench facing Kiren and Ram's desk. The chairman extracts a pair of large glasses from a pocket in his tired brown jacket, puts them on (they look too big for his small face); he takes his wrist watch off; he puts it back on; he smiles at staff as they laugh at Mahanta's joke. 'I'll get a stool to sit down' I announce but Mahanta interjects 'you can sit down on the bench!' - and he shuffles closer to the SCO chairman, making room for me to sit next to him. 'You should put a stone in your nose' he suggests. 'A small one then, not a big one' I reply and he, chuckling 'no, not big or your nose will become like [he flattens his nose with his finger]!' I say that some people put stones in both nostrils, and I'd heard from my landlady that one amrikan (Western, North American) volunteer who used to work here had put a ring through her nose [I ring my

\footnotetext{
${ }^{2}$ This view is heavily qualified in the remainder of the chapter in my $\mathrm{PhD}$ thesis, but is not detailed here as it is not germane to the paper's argument.
} 
fingers around my septum] and they do it with a needle here! Mahanta says 'it's a bhulaki' and, turning to the SCO chairman 'what do they call that here?' 'A bhulaki' the chairman corroborates.

Arjun, the FO chief, comes in, the chairman stands up and moves towards the desk where Arjun is talking with Kiren: 'it's a quarter to one, is the report finished?' The chairman stands, with his hands behind his back and addresses Arjun in the local language. Arjun leaves the room, the chairman follows him. A few seconds later, I pop my head through Arjun's door, but cannot see the chairman anywhere, so I return to the bench in the front room. Kiren comes out of Arjun's room, straight through the front room and back out of the back of the office. It's 12.50p.m. A few minutes later, Kiren is back and I ask 'what did the SCO chairman want?' 'I don't know' Kiren replies 'ask Basanta'.

I'm still in the front room. Then a man, thin, dark, with longish hair comes through the gate and stands outside the front room, clutching a chicken. Kiren and Ram are back at their desks, negotiating the finer points of format filling; they do not notice the man...

\section{Post-fieldwork: shifting emotional emphasis}

Today, upon reading this and similar passages, I am struck by their cynicism. To be sure, cynicism, suspicions of inauthenticity-deceitfulness, even-were a salient element of the public discourse about NGOs in Nepal. ${ }^{3}$ At the time of research, NGOs were widely suspected - and accused - of corruption and being profit-motivated. Questions over whom NGOs were truly benefiting were fuelled by reports of the considerable sums that had been made available to the non-governmental sector since the 1990s and also of high NGO salaries. ${ }^{4}$ If their reputation for being 'dollar-farmers' (dollar-kheti) was not always deserved, NGO fieldworkers often played down indications of wealth and privilege for the sake of keeping good working relations with project beneficiaries and local dignitaries. As a mood or emotion, cynicism also pervaded the experience of everyday life as a member of staff of a Nepali NGO. But, and this is the point, it was not the only one. The emotional experience of the protagonists in the story above ranged from humour, anxiety, and excitement to boredom and, not featured here, loneliness, longing, pain and hardship (dukha) - and included less avowable sentiments such as irritation or even antipathy. In the 'post-fieldwork' phase, by contrast, cynicism suffused my recollections and re-readings of the 'raw' fieldnotes and, subsequently, the choice of details and themes in writing up the ethnographic text.

\footnotetext{
${ }^{3}$ Significantly, perhaps, it was also a feature of the anthropological engagement with development. In this latter respect, it is telling that the critical yet sympathetic stance of Mosse's recent (2005) book on development was singled out for particular praise by the book's reviewers. The specific emotional tone of pre-existing literature or the approach to a given subject no doubt has a significant bearing on the way the novice anthropologist frames and writes about her field experience.

${ }^{4}$ In 1997, it was estimated that the total funds channelled through Nepali NGOs amounted to US\$150 million while the total official development assistance to Nepal totalled US\$391.8 million and the vast majority of Nepali NGO were almost wholly financed by international NGOs. In some NGOs, the difference in wages between the public and NGO sector was considerable: In 2001, the wages of NGO and government workers on average ranged between US\$600-2500 and US\$80-120, respectively (Dahal 2001).
} 
A second sentiment - a sense of indebtedness and guilt, and a sense of power - that was not a feature of the fieldwork experience, insinuated itself into the 'post-fieldwork' phase and blossomed as this period unfolded. A balance of power loaded in favour of the researcher was certainly not a feature of my experience of the field. While not exactly feeling 'powerless', I nonetheless felt, throughout the period of research, that I needed to tread carefully, and that access was conditional and could be withdrawn by management at various levels of the organisation. It was effectively withdrawn in one NGO when I was encouraged to leave the field by NGO managers after a stay of just over three months. I am unsure, to this day, what mischief I may have caused..$^{5}$ My point here is that in the 'post-fieldwork' phase, some emotions came to dominate recollections of the field and representations of it. Some, that were experienced during the fieldwork period, became accentuated (or 'hypercognised' to use Levy's term; Levy 1984). Others were suppressed or 'hypocognised' (ibid) and yet others, which were not experienced during that period, were introduced.

The suppression of emotionality from written accounts of fieldwork has been noted by many. Fieldwork, observed Heald and Deluz (1994), has traditionally produced two accounts: one that could be told, one that could not. The one that could be told was deemotionalised, and 'in the same way, the anthropologist was expected to come back to join the community of scholars, now as an initiate, but bearing little trace of the experience in his or her person' (ibid:10). Pratt (1986) qualifies this somewhat: she notes that personal accounts of the field experience have been recognised as a sub-genre of ethnographic writing, but it generally accompanies a formal ethnography, and it is the latter account that counts as professional capital and authoritative representation. Personal narrative, on the other hand, is deemed self-indulgent and trivial. Kleinman and Copp (1993) concur: they write that the development of 'right feeling' towards the subjects of research - an appropriate closeness during fieldwork and appropriate 'lack of emotion' during analysis - is an important part of the ethnographic endeavour.

However, these accounts present only half the story of post-field emotion work. In the case recounted here, emotion work involved not merely a suppression of feelingalthough certain feelings were certainly suppressed-but a change of emphasis, amounting to the development of a new, distinctive emotional style. I experienced an increasing distancing and empowerment, as feelings of cynicism and indebtedness were encouraged. Other emotions, by contrast, particularly pain or the sense of having been 'hard done by' by 'informants', were dismissed as 'whingeing' and effectively delegitimised - the implication of these emotional experiences lost to analysis. The emotion work carried out during and after fieldwork reinforced the sense of Othernessinformants and I no longer shared feelings: emotions that intimated a degree of 'sharing' were displaced by ones indexing hierarchy and inequality. The feeling of indebtedness (however commendable) contributed to this, as it amounted to a denial of the reciprocity of day-to-day relations in the field. This emotion work also introduced a sense of inequality. Indeed, I was no longer part of a landscape of power that was ever-fluctuating,

\footnotetext{
5 I would like to believe, however, that my 'expulsion' was tied to problems of appropriate categorisation that, Gellner and Hirsch (2001:5) note, can arise as the anthropologist strives to acquire 'insider status' within the organisation, challenging existing procedures for dealing with 'outsiders'.
} 
but in a definite position of power: feelings of (occasional) powerlessness or vulnerability gave way to feelings of powerfulness.

\section{Regimenting emotion: pedagogic practice and the construction of post-field emotional styles}

The fact that the post-field emotion work might involve a shift in emphasis rather than suppression casts doubt over the most commonly given explanation for the change in emotional content of the researcher's relation to her field in the 'post-field' phase. The authors mentioned above typically put the change in emotionality down to the pervasiveness of the ideology of 'scientistic' objectivity, and speak vaguely of the individual's need to appear competent and confident of his or her findings (Kleinman and Copp 1993). Heald and Deluz's comment is equally imprecise: 'returning from the field, many anthropologists of this generation found that they had no one to talk to about their experiences; they were encouraged to forget, to regain the distance that had been compromised in the field' (1994:10, my emphasis). Nowhere is the source of the individual's need or the origin and nature of the encouragement they note, spelt out. While a sensitivity concerning the 'soft' ('impressionistic' or 'anecdotal') nature of ethnographic data might explain the motivation to 'suppress' emotionality from texts, it does not seem satisfactory to explicate the act of suppression. What's more, even if we are willing to accept that a desire or pressure to conform to the ideals of objectivity might account for the suppression of feeling, it cannot explain the emergence of new feelings, as described above. What is needed is a better sense of the cultural mechanisms that work to shape the researcher's emotions and to produce the new 'post-field' emotional style mentioned above.

In my own case, I found the seminar to be among the practices that worked to encourage particular emotional styles. A key part of academic apprenticeship and a site for the production of anthropological knowledge, the seminar was also an important site for the production of emotional styles. The seminar fostered the development of a specific emotional style in several ways. Firstly, through explicit injunction. This is illustrated by Barry's contribution to a previous Anthropology Matters issue, 'Identity/identities and fieldwork: studying homeopathy and Tai Chi "at home" in South London'. In the account of her slow disengagement and growing scepticism towards the subject of her research, 'post-fieldwork', Barry highlights how departmental seminars offered an opportunity for explicit admonition and proffering of textbook warnings against 'going native' (e.g. Bernard 1995).

In December I gave a paper to the anthropology department and talked about my embodied experiences of Tai Chi as a participant observer. The feedback from colleagues included the observation that I seemed to have had some kind of conversion experience, and that I was insufficiently reflexive about my experiences. I experienced the sub-text as 'Oh no, she is going native'. (Barry 2002)

A second instrument of emotional 'suppression' or change of emphasis was more implicit: it consisted of the privileging of particular modalities of expression. The aversion (or unease) of academic fora towards the expression of 'the personal', and by 
extension, 'feelings' - seen to belong to the realm of 'the personal' in Western cultural settings, as Deluz and Heald (1994) point out—was also noted by Okely (1996). She writes: 'women are often less inhibited about exploring and expressing the personal element although they may apologise for this in academic debate' (ibid:29, my emphasis). What Okely's point highlights is that the 'personal' is unacceptable as a mode of debating in face-to-face academic exchanges, as well as being unacceptable as an expressive mode in writing.

The above could have been written about my $\mathrm{PhD}$ seminar experiences. Personal anecdotes were not encouraged (nor sought: 'I'm not interested in reading about Celayne', was a classmate's remark to my enthusiasm about the potentials of autoethnography; e.g. Ellis and Bochner 2000). It was also clear to (some, at least) participants in such fora that the preferred linguistic modalities and interpersonal styles in seminar settings (with a tendency towards the expository rather than the exploratory, the propensity to offer extended commentary rather than the invitation to dialogue), did not lend itself well to the expression of the 'personal' - with the exception, that is, of feelings of debt, power, and responsibility, which were cultivated through the invitation to be 'reflexive' about the experience of fieldwork. Another mechanism was simply the refusal (by teachers or mentors) to engage in talk about emotions or emotionally toned conversations: in this way, it was learnt that emotion talk was 'not relevant' to the academic task at hand.

I should also point out that the suppression of emotion and encouragement of detachment was not effected through prohibition alone. Another mechanism was through 'humour', which, while not explicitly encouraged, was always welcome, a relief during late Friday seminar sessions. Humorous quips more often than not involved the narrator laughing at herself, and further encouraged detachment from the fieldwork experience - the simultaneous creation and repudiation of a 'fieldwork self' distinct from Heald and Deluz's 'initiate' self (see above) reintegrated in the community of scholars.

I cannot comment with certitude about the mechanisms that nurtured the other feelings of which I write (feelings of power, as opposed to powerlessness; of indebtedness; and responsibility). But Reddy's concept of 'emotives' (see above) suggests that the repeated encouragements to give expression, in writing and in speech, to our own privilege (as Western, middle-class, white, researchers) and responsibilities attendant upon it might have contributed to the growth of these feelings. Similarly, Levy's (1984) concept of hypocognition suggests that we should look to the degrees of symbolic elaboration of these emotions within seminar settings in order to understand this process. Although I lack detailed material on this subject, I would like to offer the reader my conviction that a detailed exploration of academic practices would be instructive in this regard, and that our understanding of the contribution of anthropological practice to processes of Othering would be enriched by it.

\section{Final observations}

To summarise, then, I have argued, first of all, that too little attention has been paid to the role of emotions and emotion work in literature exploring the construction of 'the field' in general, and as distant and separate from personal areas of activity, in particular. I also 
noted that this body of work gives the academic institutional context all but the most cursory of treatments. Turning then to the post-fieldwork changes in emotionality, I noted that what was occurring was best described as a change in emotional emphasis rather than, as the literature contends, a suppression of feeling. I noted, too, that this change in emphasis contributes to the Othering of field subjects (and experiences), and also to the researcher and 'researched' being recast in a hierarchical relation to each other. In the final section, I sought to draw attention to the academic institutional mechanisms generating the emotional shifts I described. I commented on the role of certain academic practices in this process, and the explicit as well as implicit processes through which these shifts were realised.

Even if the change in emphasis that I describe does not resonate with the reader's experience, I hope she will agree that the suppression of emotion-which has been more widely documented - has not received adequate attention within our discipline. Neither the mechanisms of this suppression nor the implications have been sufficiently explored. I hope, at least, to have demonstrated that this is an area that is deserving of further scrutiny, and that we need to explore more fully the 'suppression of emotion' in anthropological practice; and, also, that we need to broaden our exploration of the researcher's changing emotional relation to the field and subjects of research to include the cultivation of emotion post-field.

A further point, which has emerged as I wrote this piece, is a suspicion that the kind of anthropological practice in which accounts of the construction of the categories of 'the field' and 'fieldwork' are grounded, is that of professional, academic, anthropology. Not all anthropology, of course, is practised in this way. Contributors to a recent volume (Dresch, Wendy and Parkin 2000) suggest that we need to make finer distinctions within the category 'fieldworker', distinguishing the novice and seasoned fieldworker. Longterm fieldwork, they remarked, brings with it dilemmas and challenges peculiar to it and not shared by the archetypal 'novice fieldworker'. Similarly, in order to fully understand the ways in which the field is constructed and interrogate the processes of Othering they entail, our reflection should begin to take into account the many and diverse contexts of anthropological practice today - be they within academic departments or the commercial sector, practiced in a professional capacity or during apprenticeship, through an approach that draws on a single discipline or one that is more trans-disciplinary in character.

\section{References}

Amit, V. (ed.) 2000. Constructing the Field: Ethnographic Fieldwork in the Contemporary World. London: Routledge.

Austin, J.L. 1962. How to Do Things With Words. Cambridge, Mass.: Harvard University Press.

Barry, C. 2002. Identity/identities and fieldwork: studying homeopathy and Tai Chi 'at home' in South London. Anthropology Matters Journal 4 (http://www.anthropologymatters.com/journal).

Beatty, A. 2005. Emotions in the field: what are we talking about? Journal of the Royal Anthropological Institute 11(1), 17-37. 
Bernard, H.R. 1995. Research Methods in Cultural Anthropology. Newbury Park, CA, and London: Sage Publications.

Chodorow, N. 1999. The Power of Feelings; Personal Meaning in Psychoanalysis, Gender, and Culture. New Haven: Yale University Press.

Clifford, J. and G.E. Marcus (eds.) 1986. Writing Culture: The Poetics and Politics of Ethnography. Berkeley: University of California Press.

Cohen, A.P. 1994. Self Consciousness: An Alternative Anthropology of Identity. London: Routledge.

Coleman, S. 2004. Abstracts, ASA Annual Conference: Locating the Field: Metaphors of Space, Place and in Anthropology. Durham, 29 March - 1 April.

Dahal, D.R. 2001. Civil Society in Nepal: Opening the Ground for Questions. Kathmandu: Center for Development and Governance.

Dresch, P., W. James and D. Parkin (eds.) 2000. Anthropologists in a Wider World: Essays on Field Research. Oxford: Berghahn.

Ellis, C. and A.P. Bochner. 2000. Autoethnography, personal narrative, reflexivity: researcher as subject. In Handbook of Qualitative Research (eds.) N.K. Denzin and Y.S. Lincoln, 733-768. Thousand Oaks: Sage.

Gellner, D.N. and E. Hirsch. 2001. Introduction: ethnography of organizations and organizations of ethnography. In Inside Organizations: Anthropologists at Work. (eds.) D.N. Gellner and E. Hirsch, 1-15. Oxford: Berg.

Heald, S. and A. Deluz (eds.) 1994. Anthropology and Psychoanalysis: An Encounter through Culture. London and New York: Routledge.

Kleinman, S. and M.A. Copp. 1993. Emotions and Fieldwork. Newbury Park, CA, and London: Sage Publications.

Kracke, W. 1987. Encounter with other cultures: psychological and epistemological aspects. Ethnos 15(1), 58-81.

Leavitt, J. 1996. Meaning and feeling in the anthropology of emotions. American Ethnologist 23(3), 514-539.

Levy, R.I. 1984. Emotion, knowing and culture. In Essays on Mind, Self and Emotion (eds.) R.A. Shweder and R.A. LeVine, 214-237. Cambridge: Cambridge University Press.

Lutz, C.A. and L. Abu-Lughod. 1990. Language and the Politics of Emotion. Cambridge: Cambridge University Press.

Mosse, D. 2005. Cultivating Development: An Ethnography of Aid Policy and Practice. London: Pluto Press.

Obeyesekere, G. 1990. The Work of Culture: Symbolic Transformation in Psychoanalysis and Anthropology. Chicago: University of Chicago Press.

Okely, J. 1996. Own or Other Culture. London and New York: Routledge. 
Pratt, M.L. 1986. Fieldwork in common places. In Writing Culture: The Poetics and Politics of Ethnography (eds.) J. Clifford and G.E. Marcus, 27-50. Berkeley: University of California Press.

Rapport, N. 2000. The narrative as fieldwork technique: processual ethnography for a world in motion. In Constructing the Field: Ethnographic Fieldwork in the Contemporary World (ed.) V. Amit, 71-95. London: Routledge.

Reddy, W. 1997. Against constructionism: the historical ethnography of emotions. Current Anthropology 38(3), 327-351.

2002. The Navigation of Feeling: A Framework for the History of Emotions. Cambridge: Cambridge University Press.

Rosaldo, M.Z. 1984. Toward an anthropology of self and feeling. In Culture Theory: Essays on Mind, Self, and Emotion (eds.) R.A. Shweder and R.A. LeVine, 137157. Cambridge: Cambridge University Press.

Wikan, U. 1992. Beyond the words: the power of resonance. American Ethnologist 19(3), 460-482.

\section{About the author}

Celayne Heaton Shrestha is currently a Research Fellow at the University of Sussex. She is investigating the implications of Nepal's 10-year insurgency for development NGOs, as part of the ESRC Non-Governmental Public Action research programme. She can be contacted at celayne1@yahoo.co.uk 